\title{
Dossiê Temático sobre Choro
}

\section{Apresentação}

\section{PEDRO DE MOURA ARAGÃO*}

Universidade Federal do Estado do Rio de Janeiro

Universidade de Aveiro

U

$m$ dos gêneros populares urbanos mais antigos do país ainda em plena atividade, o choro teve, nas últimas duas décadas, um forte crescimento nas universidades brasileiras, tanto no que concerne à prática instrumental associada a componentes curriculares quanto no âmbito de pesquisas acadêmicas. Este fenômeno é sem dúvida tributário de um movimento crescente de intérpretes, clubes do choro, rodas e escolas associadas ao gênero, tanto no país quanto no exterior.

É cada vez mais comum encontrarmos, em diversas cidades do Brasil, jovens instrumentistas ligados ao choro que buscam o caminho universitário como forma de profissionalização - o que faz com que o gênero se cristalize como uma das "vertentes" da música popular na universidade, ao lado de outros gêneros como a bossa-nova, o jazz o samba e o forró. Este processo de institucionalização é sem dúvida acompanhado de visões muitas vezes polarizadas entre aqueles que saúdam o acolhimento destes gêneros como símbolos de uma abertura da universidade brasileira para outras músicas para além da música de concerto e aqueles que criticam o que seria um processo de reificação e "congelamento" de práticas populares através dos currículos universitários.

\footnotetext{
* Pedro de Moura Aragão possui Bacharelado em Regência pela Universidade Federal do Rio de Janeiro (2002) e Mestrado em Música pela Universidade Federal do Rio de Janeiro (2005). Doutor em musicologia pela UNIRIO, é professor Adjunto nível 4 da mesma instituição. Sua tese de doutorado, "O Baú do Animal: Alexandre Gonçalves Pinto e o Choro", foi contemplada com o Prêmio Funarte de Produção Crítica em Música 2012 e com o Prêmio Silvio Romero 2011 (2a colocação). Desenvolve pesquisas na área de etnomusicologia, com ênfase na questão de arquivos de música popular urbana brasileira, tendo desenvolvido projetos de pesquisa em parceria com diversos instituições no Rio de Janeiro, como o Museu da Imagem e do Som e o Instituto Moreira Salles. Coordenador do projeto de extensão Escola Portátil de Música, referência do ensino do choro no Rio de Janeiro. Como bandolinista, tem grande atuação no mercado nacional, tendo atuado em shows e gravações com cantores como Roberto Silva, Cristina Buarque, Zélia Duncan, Mônica Salmaso, além de ter atuado como solista e intérprete em concertos na França, Bélgica, Dinamarca e Colômbia. E-mail: pmaragao@gmail.com
} 
Este mesmo processo de institucionalização também faz com que se multipliquem monografias, trabalhos de conclusão de curso, dissertações e teses sobre choro em diversas áreas como musicologia, etnomusicologia, estudos de performance, estudos de música popular e análise musical. Na maior parte das vezes tais textos têm como autoria estudantes que são eles/elas mesmos(as) intérpretes de choro, em um movimento que Salgado (2014) identifica como sendo de “alteridade mínima”, com base em conceito de Peirano (2006). Como diz o autor, "muito do que vem sendo pesquisado, por músicos que ingressam num programa de pós-graduação, diz respeito ao próprio campo de trabalho e as suas posições nesse espaço social" (2014, p.9).

A proximidade entre pesquisadores e seus objetos de pesquisa, no caso específico do choro, apresenta ao mesmo tempo vantagens e perigos que devem ser analisados no âmbito deste crescente corpus de estudo. Se por um lado o intérpretepesquisador apresenta um conhecimento empírico e uma vivência "de campo" que indubitavelmente facilitam o processo de pesquisa, por outro lado esta mesma condição de insider pode trazer riscos relativos à falta de distanciamento crítico em relação a discursos nativos. Trabalhos meramente calcados em aspectos biográficos e laudatórios de músicos e trajetórias musicais, bem como trabalhos que - para citar mais uma vez Salgado (2014:16) - acabam por "reafirmar aquilo que se conhecia anteriormente e exteriormente ao processo de pesquisa", são alguns exemplos advindos dos perigos possíveis desta condição de "alteridade mínima".

Um outro aspecto bastante sensível em uma breve análise sobre estudos que têm o choro como enfoque é a questão do nacional-popular. Não há dúvida de que os primeiros estudos sistemáticos sobre este gênero musical foram publicados por autores que se alinhavam ao ideário nacionalista que tem raízes no modernismo brasileiro, calcado na utilização de práticas musicais rurais e folclóricas como substrato para a criação de uma "música artística" nacional (Andrade, 1928). Posteriormente adaptado para o contexto da música popular urbana a partir dos anos 1950 (Napolitano e Wasserman, 2000) tal modelo seria caracterizado por autores que na maior parte das vezes estavam ligados ao jornalismo e que teriam muitas vezes uma "atuação militante" na construção da ideia do samba e do choro como gêneros “autenticamente nacionais”. Nomes como Lúcio Rangel, Ary Vasconcelos e José 
Ramos Tinhorão (este último fortemente influenciado pela abordagem do materialismo-histórico), se por um lado tiveram atuação fundamental no levantamento de fontes, dados e análise das condições socioculturais ligadas ao aparecimento do gênero (especialmente Tinhorão), ao mesmo tempo contribuíram para a construção de discursos nativos calcados em ideais de autenticidade e legitimidade do choro em detrimento de outros gêneros musicais praticados no Brasil. Se este paradigma deixou de ser hegemônico há décadas (Travassos, 2003), permanece ainda em parte da produção acadêmica associada ao gênero, a busca por "origens" e pela tentativa de identificação de traços estilísticos de cada uma das "raças" formadoras que dominava a cartilha modernista.

Estas breves reflexões aqui apresentadas não têm qualquer pretensão de realizar um balanço sistemático da literatura recente sobre choro, mas apenas procuram apontar algumas questões sensíveis sobre esta produção. Em que pesem estes pontos críticos, é inegável que vários trabalhos recentes têm superado paradigmas antigos, trazendo importantes contribuições para o conhecimento acadêmico sobre o choro, como é o caso dos cinco artigos que integram o presente dossiê da Música Popular em Revista.

Escritos por autores que também são intérpretes atuantes no cenário do choro - em condição de "alteridade mínima", como mencionamos anteriormente estes estudos, no entanto, se utilizam das ferramentas e percepções de músicos para construir conhecimento crítico e significativo sobre questões técnicas ainda não exploradas por estudos acadêmicos na área. No artigo "O Piano no grupo de choro: outras possibilidades", Luísa Mitre procura analisar ferramentas interpretativas utilizadas por Cristóvão Bastos e Laércio de Freitas - dois dos mais importantes pianistas brasileiros da atualidade - em contextos coletivos de performance. Utilizando-se de um recurso que é sem dúvida fundamental para os estudiosos da música popular - a análise de fonogramas - Mitre aborda o uso do contraponto e de recursos timbrísticos do piano em gravações com regionais de choro. A autora apresenta não apenas transcrições e análises destes procedimentos, mas também as próprias reflexões de Cristóvão Bastos e Laércio de Freitas sobre suas práticas, através de entrevistas concedidas especialmente à pianista-pesquisadora. 
Em “A construção estilística do cavaquinho e os processos de transmissão musical no choro: a relação Galdino-Álvares-Canhoto", Jamerson Farias procura lançar novas luzes sobre três cavaquinhistas extremamente relevantes na história do choro no Rio de Janeiro: Galdino Barreto, Mário Álvares e Waldiro Tramontano, o "Canhoto". Por ser um instrumento totalmente imerso na tradição oral - as "levadas" do cavaquinho jamais eram escritas, e sim repassadas oralmente nas rodas de choro (como acontece até hoje, aliás) - vários procedimentos de performance do instrumento permanecem pouco analisados e estudados em trabalhos acadêmicos. Mais uma vez, a análise de fonogramas é utilizada aqui como ferramenta indispensável para o estudo de procedimentos estilísticos de Canhoto - já que infelizmente não existem gravações em que os cavaquinhos de Galdino Barreto e Mário Álvares sejam audíveis. Calcado no estudo de Sandroni (2001) sobre as alterações rítmicas produzidas no bairro do Estácio de Sá nos finais dos anos 1920, Faria procura analisar "levadas" rítmicas características de Canhoto e ao mesmo tempo tenta estabelecer possíveis linhas de parentesco musical com os legados de Barreto e Álvares.

“A Retórica Musical e o Choro", de Mário Séve, é um estudo analítico de ferramentas da teoria das tópicas e de elementos da retórica musical dos períodos barroco e clássico aplicados ao choro. Através de uma ampla revisão de literatura sobre estes temas - que inclui uma vasta gama de autores, desde Monteverdi até Harnoncourt - o autor propõe possíveis paralelos entre figuras retóricas extraídos de obras barrocas e peças do repertório do choro, em um estudo bastante acurado e repleto de transcrições musicais.

Em “As três fases do maxixe carioca", Henrique Cazes nos apresenta uma proposta de periodização e organização deste gênero que é parte indissociável do universo do choro. Frequentemente estudado em seus aspectos históricos e sociais que normalmente colocam ênfase no caráter sensual e "imoral" do maxixe na Belle Époque carioca - o maxixe é aqui analisado a partir de perspectivas estritamente musicais, com base em análises de gravações do início do século e especial ênfase nas chamadas "levadas" - termos utilizado pelos músicos de choro para nomear o acompanhamento rítmico-harmônico. 
Finalmente, o artigo “Improvisação idiomática em música brasileira: relato da implementação de uma disciplina no ensino superior" de Almir Côrtes é resultado de uma pesquisa de pós-doutorado realizado na UNICAMP, que tinha por objetivo a elaboração de um programa de curso voltado para a improvisação na música popular brasileira. Tomando como estudo de caso a análise de dois semestres do curso proposto, o autor procura relacionar procedimentos de improvisação do choro com o de outros gêneros da música brasileira, como frevo, samba e baião. Utilizando-se de conceitos propostos por autores como Barry J. Kenny e Martin Gellrich, Côrtes se utiliza de uma "auto-avaliação" de campo para entender processos didáticos e aplicações práticas de conceitos de improvisação em um componente curricular universitário.

Desejamos a todos uma excelente leitura!

\section{Referências Citadas}

ANDRADE, Mário de. Ensaio sobre a música brasileira. São Paulo: Martins Fontes, 1962 [1928].

NAPOLITANO, Marcos; WASSERMAN, Maria Clara. Desde que o samba é samba: a questão das origens no debate historiográfico sobre a música popular brasileira. Revista Brasileira de História, v.20 (39), p. 167-189, 2000.

PEIRANO, Mariza. A teoria vivida - e outros ensaios de antropologia. Rio de Janeiro: Jorge Zahar, 2006.

SALGADO, José Alberto. Questões de método e interlocução em pesquisas com práticas de música. El Oído Pensante, v. 2, n. 2, 2014.

TRAVASSOS, Elizabeth. Esboço de balanço da etnomusicologia no Brasil. Opus, v. 9, p. 73-86, 2003. 